\title{
Urban Agriculture and Household Welfare: Evidence from Hossana Town, Ethiopia
}

\author{
Abraham Tessema Handalo Jemal Abafita \\ Department of Economics, Jimma University, Jimma, Ethiopia
}

\begin{abstract}
Background: Urban Agriculture plays a very important role in decreasing hunger and poverty contributing towards sustainable food production and promoting the integration of environmental values in development. Despite its significant role in fulfilling the basic demand of low-income families, however, it continues to get far less attention and lacks the rightful place among policy-makers, urban planners, and authorities. We analyze households' participation in urban agriculture and its effect on household welfare in Southern Ethiopia using cross-sectional data collected from a sample of 176 households in Hossana Town. Descriptive statistics, binary logistic regression and propensity score matching techniques were used for data analysis. Results: The results revealed that participation in urban agriculture was higher for households with older and female heads and was associated with higher level of nonfarm earnings compared to nonparticipation, with the difference being statistically significant at $5 \%$. On the other hand participating families had a significantly fewer family members, lower access to credit, extension services, and decreased supply of improved input than their non-participating counterparts. Participation was also found to be associated with smaller land ownership and lower access to water, the differences being significant at 5\%. Indeed, results of the binary logistic regression indicated that access to credit, access to extension services, access to improved inputs, household size, access to water except income from other sources were important factors significantly enhance participation in urban agriculture practice in Hossana Town. On other hand, propensity score matching model showed that urban agriculture has a positive significant impact on poverty reduction. It was indicated by using two proxy of urban household poverty status (wellbeing) that is consumption expenditure per adult equivalent and asset building per capita. Conclusion: The results indicates that urban agriculture is constrained by a number of factors among which access to credit, access to extension services, access to improved inputs, household size and non-farm income were the major ones.. Furthermore, our analysis reveals that participation in urban agriculture has a significant positive impact on consumption expenditure per adult equivalent. This indicates the direct role of participation in urban farming on improving household welfare.
\end{abstract}

Keywords: Binary logistic model, Hossana Town, propensity score matching, Ethiopia, urban agriculture, urban poverty

DOI: $10.7176 / \mathrm{JESD} / 11-5-06$

Publication date:March $31^{\text {st }} 2020$

\section{Background}

In view of the mismatch between the increasing urban populations and the availability of employment opportunity in industrial or manufacturing sectors, coupled with the lack of formal jobs in many African cities; urban agriculture has been serving as an important source of employment for the urban poor and a vital employment opportunity for urban people (Arku et al., 2012)

In Ethiopia, poverty is widespread, deep-rooted and complex in nature and constitutes the priority development challenge of the country. It is high agenda of the government, donor agencies, NGOs and other actors who are committed to reduce its level and mitigate its effect associated impacts on the wellbeing of the people. Although the government has been implementing various policy interventions and programs that are in one way or another related to poverty reduction, these efforts have been mostly biased towards rural areas (Esubalewu, 2006).

According to data from the 1999/2000 Household Income, Consumption and Expenditure (HICE) and Welfare Monitoring (WM) Surveys of the Central Statistical Agency (CSA), about 44 percent of the total population (45\% in rural and $37 \%$ in urban areas) were found to be below poverty line. The corresponding figure from the 2004/05 surveys stood data bout 39 percent with the rural and urban rates being respectively $39.3 \%$ and $35.1 \%$ (CSA, 2012).Expenditure on food and non-food essentials was the lowest among households living in SNNPR and Amhara, with over a quarter of households (26\%) in SNNPR categorized in the lowest consumption/expenditure quintiles while in Amhara the corresponding figure was 22\% only(WFP, 2014)

Recently; however, there are encouraging developments in urban agricultural practices. Ethiopia has started the implementation of urban agriculture as a strategy of urban poverty reduction (Dereje, 2011).

However, there is little information on urban agriculture practice and its potential impact on poverty reduction. In particular, there is dearth of empirical evidence pertaining to the extent of participation in urban agriculture and the possible role it plays in improving household welfare in Hosana town. The purpose of the current study is, therefore to examine factors affecting participation in urban agriculture and evaluate its impact on poverty 
reduction among households in the study area.

\section{Methods}

\subsection{Description of the Study Area}

The study was conducted in Hossan Town. It is located southwest of Addis Ababa at a distance of $232 \mathrm{~km}$ on theAlemgena-Butajira route and at about $168 \mathrm{~km}$ southeast of Hawassa (the capital of SNNPR) on the HalabaAngeca road. The town is home to about 97,184 people of which 49,322 (50.8\%) and 47,863 (49.2\%) are estimated to be male and female respectively. With an annual average population growth rate of $10.4 \%$ and a mean of 2484 people per $\mathrm{km}^{2}(\mathrm{CSA}, 2014)$ it is also one of the most densely populated areas in the country with. The town covers an altitude range of 2140-2380m above sea level, having a bimodal rainfall: small rains from March to May and heavy rains during the months of late June and August. The five years' (2009-2013) mean annual rainfall and temperature were $1121.3 \mathrm{~mm}$ and $18.50 \mathrm{C}^{\mathrm{o}}$ respectively. The town is mainly characterized by highland 'Weynadega' climatic conditions. The predominant farming system of the area is a mixed type involving crop and livestock production where crops contribute a larger share to household's income (Hossana Town Finance and Economic Development Office, 2014).

\subsection{Sampling Procedures and Sample Size}

The study was conducted in three kebeles of one sub town A multi-stage sampling technique was employed to draw sample households. In the first stage, a sub-city called Gofermeda was randomly selected from among three of the sub-cities of the town. In the second stage, three kebeles namely,J-naram okebele, Heto kebele and Bobicho were selected purposively due to their high potential for urban agriculture practice. In the third stage, a total of 176 household heads ( 83 participants and 93 non- participants) were selected based on probability proportional sampling (PPS) technique from the sampled kebeles using simple random sampling for non-participants whereas stratified random sampling for participants. The actual sample size (n) was calculated using the simplified formula of Yemane(1967).

$$
n=\frac{N}{1+e 2(N)}
$$

Where, $\mathrm{n}=$ sample size, $\mathrm{N}=$ Total household heads, and $\mathrm{e}=$ level of precision $(0.07)$

Using a $95 \%$ confidence level, 0.5 degrees of variability and $7 \%$ level of precision the final sample size became

$$
n=\frac{1321}{1+.07^{2}(1321)}=176
$$

Thus, 176 sample household heads were selected from total population in this study.

Primary data collection was conducted using structured questionnaire and semi-structured questionnaire. Four enumerators who have adequate knowledge about the area and well acquainted with the culture and language were recruited. They were trained on the methods of data collection and contents of the questionnaire. Secondary data was collected from relevant literature, reports of Agricultural and Development Department and Office and other publications.

\subsection{Data Analysis}

The data were analyzed using STATA version 13. The important descriptive statistical tools were used to describe and summarize the data. Binary logit model was employed to examine the determinants of participation in urban agriculture, where the dependent variable - urban agriculture (ua) - defined as a dummy variable equals 1if the household is participant, and 0 otherwise; and the independent variables (Xi) are defined as a vector of factors affecting urban households' participation in urban agriculture in the study area. Furthermore, the impact of urban agriculture on household welfare was evaluated by through propensity score matching method. For this part of the analysis, we used consumption expenditure per adult equivalent (CEAE) and asset building per capita(ABC) as proxy to household wellbeing.

Following Rosenbaum and Rubin (1983) the Average Effect of Treatment on the Treated (ATT) for the sample households is given by:

$\mathrm{ATT}=\mathrm{E}\left(\mathrm{Yi}^{\mathrm{T}}-\mathrm{Yi}^{\mathrm{C}} \mid \mathrm{Di}=1\right)=\mathrm{E}\left(\mathrm{Yi}^{\mathrm{T}} \mid \mathrm{Di}=1\right)-\mathrm{E}\left(\mathrm{Yi}^{\mathrm{C}} \mid \mathrm{Di}=1\right)$

Where, ATT $=$ Average Treatment on treated, $\mathrm{E}\left(\mathrm{Yi}^{\mathrm{T}} \mid \mathrm{Di}=1\right)=$ Average outcomes for individual, with treatment, if he/she would participant $(\mathrm{Di}=1), \mathrm{E}\left(\mathrm{Yi}^{\mathrm{C}} \mid \mathrm{Di}=1\right)=$ Average outcomes for individual, with treatment, if he/she would non-participant( $\mathrm{Di}=1)$.

\section{Result and Discussion}

\subsection{Descriptive Statistics}

Table1 reports the socio-economic/demographic characteristics of the sample households by participation status . Slightly over half $(51.7 \%)$ of the sampled households were male-headed. Participation status showed significant difference $(\mathrm{p}<5 \%$ ) by sex of the head with $60.2 \%$ male-headed households practicing urban farming compared to 
only $39.8 \%$ for female-headed families.

Table 1: Sample households by sex of the head and participation status

\begin{tabular}{lllll}
\hline Participation status & Female & Male & Total Sample & P-value \\
Participants & $33(39.8 \%)$ & $50(60.2 \%)$ & $83(100 \%)$ & \\
Non-participants & $52(55.9 \%)$ & $41(44.1 \%)$ & $93(100 \%)$ & $0.032 * *$ \\
Total & $85(48.3 \%)$ & $91(51.7 \%)$ & $176(100 \%)$ & \\
\hline
\end{tabular}

** Statistically significant at 5\% based on Pearson's chi squared test

Source: Own computation, 2019

The main source of credit in the study area is cooperatives, Omo microfinance, and relatives. Table 2 showed that from the sample households $29.5 \%$ have got credit while $70.5 \%$ did not take credit. There are various factors which hinder households not to take credit. In fact, some of them are food consumptions rather than farm inputs consumption and unexpected expenditure, existing of high- interest rate and by having enough money to buy agricultural inputs. When we compare to participants with non-participants is $39.8 \%$ and $20.4 \%$ got credit respectively. On other hands, $60.2 \%$ of the participant and $79.6 \%$ non-participant households did not take credit. Thus this shows there is a relatively high difference between participants and non-participants in terms using credit access. It is also statistically significant at $1 \%$.

As result of (Table 2), about $73.3 \%$ of the sample households do not get extension service. When we compare to participants with non- participants, the majority of the participants $(38.6 \%)$ households get support from extension agents. Extension service here refers to advice, technical training, and sharing experience. About $38.6 \%$ treated group and $16.1 \%$ control groups consult extension agents whenever they need technically related with urban agriculture. From the respondents, about $61.4 \%$ of the participants and $83.9 \%$ non- participants reply they do not get extension service. It is statistically significant at $1 \%$.

According to (Table 2), about $72.7 \%$ of the sample households did not use improved agricultural inputs, $27.3 \%$ of sample households' user of as improved agricultural inputs. When we compare to participants with nonparticipants' households, the majority of the participants' households used as improved agricultural inputs to improve agricultural products. According to, the survey about $41 \%$ of participants and $15 \%$ non-participants used as improved agricultural inputs. Agriculturally improved technologies are recommended inputs, varieties of improved seeds, improved diseases and pest management which are used to improve agricultural products.

About 59\% treated group and 85\% control groups did not use improved agricultural inputs which mean they use as their own desires. It is also statistically significant at $1 \%$.

According to (Table 2), about $71.6 \%$ of the sample households did not have water access, $28.4 \%$ of sample households' had water access. When we compare to participants with non- participants the majority of the participants' households had water access to participate in urban agriculture. According to, the survey about $41 \%$ of participants and $17.2 \%$ non- participants had as water access. Water access includes having pipe water, wheel water, spring water and river in his/her residential compound or near there in order to participate in urban agriculture. About $59 \%$ treated group and $82.8 \%$ control groups did not have any access to water. It is also statistically significant at $1 \%$

Table 2: Access to various institutional services by participation status

\begin{tabular}{|l|l|l|l|l|l|}
\hline Variable (type of service) & Access & Participants & Non-participants & Total sample & P-value \\
\hline \hline \multirow{2}{*}{ Credit services } & Yes & $33(39.8 \%)$ & $19(20.4 \%)$ & $52(29.5 \%)$ & $0.005^{* * *}$ \\
\cline { 2 - 5 } & No & $50(60.2 \%)$ & $74(79.6 \%)$ & $124(70.5 \%)$ & \\
\hline \multirow{2}{*}{ Extension services } & Yes & $32(38.6 \%)$ & $15(16.1 \%)$ & $47(26.7 \%)$ & $0.003 * * *$ \\
\cline { 2 - 5 } & No & $51(61.4 \%)$ & $78(83.9 \%)$ & $129(73.3 \%)$ & \\
\hline \multirow{2}{*}{ Water } & Yes & $34(41 \%)$ & $14(15 \%)$ & $48(27.3 \%)$ & $0.000^{* * *}$ \\
\cline { 2 - 5 } & No & $49(59 \%)$ & $79(85 \%)$ & $128(72.7 \%)$ & \\
\hline & Yes & $34(41 \%)$ & $16(17.2 \%)$ & $50(28.4 \%)$ & $0.003 * * *$ \\
\cline { 2 - 5 } & No & $49(59 \%)$ & $77(82.8 \%)$ & $126(71.6 \%)$ & \\
\hline
\end{tabular}

Note: $* * *$ indicates statistical significance at $1 \%$ based on Pearson's chi square

Source: Own computation, 2019

As tabulated (Table 3), from total sample household heads, $40.9 \%$ of households have attained secondary education. The comparisons by the participation in urban agriculture revealed that $37.34 \%$ participants have attained secondary education whereas $44.09 \%$ of non-participants have completed secondary education. Thus, it shows that more than half respondents have completed primary and secondary education. Education helps households to increase productivity through promoting awareness on possible advantages of modernizing agriculture.

Thus, there is no significant difference between participants and non- participants households in term of education. Above all, it is important to note that urban agriculture is practiced by people with different education 
levels.

Table 3: Distribution of households by participation status and head's education level

\begin{tabular}{|c|c|c|c|c|c|c|c|}
\hline \multirow{2}{*}{ Description } & \multicolumn{2}{|c|}{ Participants } & \multicolumn{2}{|c|}{ Non-participants } & \multicolumn{2}{|c|}{ Total sample } & \multirow{2}{*}{ P-value } \\
\hline & & $\%$ & No. & $\%$ & No. & $\%$ & \\
\hline Illiterate & 7 & 8.43 & 5 & 5.37 & 12 & 6.82 & \\
\hline Primary education & 15 & 18.07 & 26 & 27.96 & 41 & 23.30 & \\
\hline Secondary education & 31 & 37.34 & 41 & 44.09 & 72 & 40.90 & $0.126^{\mathrm{ns}}$ \\
\hline Above grade 12 & 30 & 36.16 & 21 & 22.58 & 51 & 28.98 & \\
\hline Total & 83 & 100 & 93 & 100 & 176 & 100 & \\
\hline
\end{tabular}

Note: $\mathbf{n s}$ indicates that non-significance (absence of association)

Source: Own computation, 2019

The average age of the sample household head was found to be 45.39 years where the minimum is 30 and the maximum is 75 (Table 4). The average household age of participants in urban agriculture is 45.07 and the corresponding figure for non-participants is 45.68. From the statistical analysis performed, it is found out that the mean age difference between participants and non- participants is much and statistically significant at $1 \%$.

Table 4 , it was also indicated that in the study area the average family size is 5 persons per household, when the minimum is 2 and maximum is 8 . When we compare the average household size between participants and nonparticipants of urban agriculture is related but there is difference. From the statistical analysis performed, it is found out to be statistically significant at 1\%. Family size in a household influences the amount of labor the household can spend on urban agriculture and the amount of food consumed.

As (Table 4) stated the land holding of the sample household varies from 0.001 hectare to 0.25 hectare. The average land holding is 0.03 hectare. The mean land holding for participants is 0.03 and the corresponding figure for non-participants is 0.02 hectare. When we compare the average land size between participants and nonparticipants of urban agriculture is related but there is difference. Therefore, the average land size for both participants and non-participants is statistically significant at $1 \%$

The average income from other sources for the sample households were found to be 2413.86birr per month where the minimum is 300 birr per month and the maximum is 7000 birr per month (Table 4). The average other income of participants of urban agriculture is 2216.40 birr per month and the corresponding figure for nonparticipants is 2590.10 birr per month. From the statistical analysis performed, it is found out that there is significant difference between participants and non-participants in other income. It is statistically significant at $\mathrm{p}<1 \%$.

Table 4: Household socioeconomic and demographic characteristics

\begin{tabular}{|l|l|l|l|l|l|}
\hline Variable & Description & Total sample & Participants & Non- participant & P-value \\
\hline Head's age & Mean & 45.39 & 45.07 & 45.68 & \multirow{2}{*}{$0.000^{* * *}$} \\
& Minimum & 30 & 30 & 30 & \\
& Maximum & 75 & 60 & 75 & $0.000^{* * *}$ \\
\hline \multirow{5}{*}{ Family size } & Mean & 4.89 & 5.04 & 4.74 & \\
& Minimum & 2 & 2 & 2 & $0.000^{* * *}$ \\
& Maximum & 8 & 8 & 8 & \\
& Mean & 0.03 & 0.03 & 0.02 & 0.001 \\
& Minimum & 0.001 & 0.002 & 0.05 & $0.000^{* * *}$ \\
\hline
\end{tabular}

Note: $* * *$ indicates statistical significance at $1 \%$ based on t-test

Source: Own computation, 2019

\subsection{Factors that Affect Participation in Urban Agriculture}

The estimates of the binary logistic regression model are presented in Table 5. The goodness fit of the model for the binary logistic regression model, an intuitively appealing way to summarize the result of the fitted logistic model is via a classification table.This cross-classification is the result of cross-classification of the outcome variable " $y$ " with a dichotomous variable whose values are derived from the estimated logistic probabilities. With regard to the predictive efficiency of the models out of 176 sample household include in the model, 128 (73\%) were correctly predicted. The sensitivity and specificity indicate that $71 \%$ of a participant of urban agriculture and $75 \%$ of non-participant of urban agriculture households were correctly predicted in their categories respectively (Annex- I). Out of ten variables included in the model, six explanatory variables were found to be significant. The possible explanations of the significant variables are as follows: 
Table 5: Binary logistic model estimates for factors affecting participation in urban agriculture

\begin{tabular}{|c|c|c|c|c|c|}
\hline Variables & Coefficient & Odds Ratio & $\mathrm{Z}$ & \begin{tabular}{l|l|}
$\mathrm{P}>$ & $\mathrm{Z}$ \\
\end{tabular} & Marginal effect \\
\hline Sex of the head (SEX) & 0.534432 & 1.706479 & 1.46 & 0.144 & 0.1320743 \\
\hline Age of the head & -0.0026498 & 0.9894035 & -0.39 & 0.698 & -0.0026498 \\
\hline \multicolumn{6}{|l|}{ Education of the head } \\
\hline Primary education & -0.3865054 & 0.679427 & -0.51 & 0.607 & -0.0949036 \\
\hline Secondary education & -0.3252433 & 0.7223516 & -0.46 & 0.648 & -0.0805403 \\
\hline Above grade 12 & 0.7046345 & 2.023107 & 0.93 & 0.352 & 0.1743573 \\
\hline Household size(HZ) & $0.3248 * *$ & 1.3838 & $2 . .32$ & 0.020 & 0.080799 \\
\hline Land size(LS) & 3.563548 & 35.28819 & 1.03 & 0.305 & 0.8863968 \\
\hline Income from other sources IOS) & $-0.000282 * *$ & 0.9997181 & -1.98 & 0.048 & -0.0000701 \\
\hline Access to credit(AC) & $0.6904981 *$ & 1.994709 & 1.71 & 0.087 & 0.17093 \\
\hline Access to water(AW) & $0.9892982 * *$ & 2.689239 & 2.35 & 0.019 & 0.2421024 \\
\hline Access to extension services(AES) & $0.9379242 * *$ & 2.554673 & 2.40 & 0.017 & 0.2301116 \\
\hline Access to improved inputs(AII) & $0.8003671 *$ & 2.226358 & 1.82 & 0.069 & 0.1973889 \\
\hline Constant term & -1.88962 & 0.1511292 & -1.05 & 0.295 & \\
\hline
\end{tabular}

Note: $* *$ and $*$ indicate statistical significance at $5 \%$ and $10 \%$ respectively

Source: Own computation, 2019

Family size is to be highly significant in determining the probability of urban households' participation in urban agriculture in the study area. This variable is positively associated with the participation in urban agriculture and significant at the probability level of 5\%. Marginal effect is 0.08 (Table 5), that implies the being other things constant, as family size increased by one person, the probability of household participating in urban agriculture increased by 8percent. This result matches with the finding of Jongwe(2013)that states increase in household size increases vulnerability and leads to households venturing into urban agriculture as a coping mechanism.

Income from other sources represents the amount of income earned from other activities rather than agriculture in cash or in kind within the year. In the study area, the household head gets a better income from other activities then there is less probability of being a venture in urban agriculture. Accordingly, in the study area, the participation of urban households and their family members in urban agriculture is highly determined by their ability to not get access to other job opportunities. The result suggests that households engaged in other activities are endowed with higher income and less likely to participate in urban agriculture. Income from other sources (other income) is negatively and significantly associated with urban households at a probability level of 5\%. The probabilities of urban households to be participating in urban agriculture decreases by a factor of 1.00 as the urban households obtain more unit of other income.

Credit is an important source of investment on activities that generate income for urban households. The households can purchase agricultural inputs like improved seeds, fertilizer, and livestock for resale after fattening. Households who have access to credit could increase their production to escape poverty. The logit model analysis revealed that credit has a significant positive association with participation in urban agriculture at a probability level of $10 \%$. Urban households who have the opportunity of accessing farm credit would build their capacity to produce more through purchasing of agricultural inputs. The households with more access to farm credits have the possibility to participate in urban agriculture than those who have no access to credit. The odds ratio in favor of participation in urban agriculture increases; other things remain constant, by a factor of 2.0as far households get access to farm credit. For instance, the non-availability of adequate credit when needed negatively impacts the farm output (Guirkinger \& Boucher, 2008).

Access to water is positively related to the participation of urban agriculture practice. This variable is significant at 5\% probability level. The Odds ratio is 2.7 (Table 5), this is that household heads who had water access are approximately three times more likely to participate in urban agriculture as compared to household heads who did not have it. Jacobi, Amend, \& Kiango( 1999) suggested that access to resources, above all water, is the major constraint for urban agriculture.

Access to improved inputs is significant at the $10 \%$ level of significance. Improved agricultural inputs refer to household heads get recommended inputs, improved seeds and improved diseases and pests management practices. The odds ratio is 2.2(Table 5), this is that households who got improved inputs are about two times more likely to participate in urban agriculture as compared to households who did not get. According to Smith etal.( 2001), lack of access to farming inputs such as seeds, fertilizers, pesticides, chicks \& heifers, feed and medicine is a major constraint facing urban farmers.

Access to extension services is positively related to participation in urban agriculture practice. This variable is significant at $5 \%$ probability level. The odds ratio is 2.6 (Table 5), this is that household heads who are involved in extension services are nearly three times more likely to participate in urban agriculture as compared to household heads who are not involved in extension services. The main reasons for possible factor in urban households' 
decision to participate in urban agriculture and their level of production since urban households receive a number of services from extension services, including technical services on its production

\subsection{Impact Analysis of Propensity Score Matching}

According to Grilli \& Rampichini ( 2011), the necessary steps when implementing propensity score matching are: Propensity score estimation, Choose matching algorithm, Check overlap/common support. Thus, to analyze the impact of participation in urban agriculture practice on urban households' consumption expenditure and their durable asset building (poverty reduction), propensity score matching with different matching algorithms namely: nearest neighborhood, caliper, and kernel matching were employed. Matching of the participant and nonparticipant households were carried out to find out the common support region. The basic principle for determining the common support region is to be deleting all observations whose propensity score is smaller than the minimum propensity scores of participants and larger than the maximum in the control group (Caliendo \& Kopeinig, 2008). That is, deleting all observations out of the overlapping region.

Table 6: Predicted propensity score common support region

\begin{tabular}{lllll}
\hline Observations & Mean & Std. Dev. & Min & Max \\
Non-participant & 0.3729129 & 0.2006117 & 0.117518 & 0.866362 \\
Participant & 0.5813284 & 0.2052649 & 0.117418 & 0.878812 \\
Total & 0.4711469 & 0.2275517 & 0.117418 & 0.878115 \\
\hline
\end{tabular}

Source: Own computation, 2019

The summary statistics of propensity scores of urban households (Table 6), the predicted propensity scores range from 0.117418 to 0.87881154 with a mean value of 0.5813284 and standard deviation 0.2052649 for the participant households, while it ranges from 0.1175179 to 0.866362 with a mean value of 0.3729129 and standard deviation 0.2006117 for those non- participant households. Accordingly, the common support region was satisfied in the range of 0.117418 to 0.866362 by dumping 23 observations (13 from those participants and 10 from those nonparticipant households)

3.5. 1.Matching Algorithms of Participant and Non-Participant Households

It is known that choice of matching estimator is decided based on the balancing qualities of the estimators. According to Dehja \& Wehba(1999), the final choice of a matching estimator was guided by different criteria such as equal means test referred to as the balancing test, pseudo-R2 and matched sample size. The balancing test is a test conducted to know whether there is a statistically significant difference in the mean value of per-treatment characteristics of the two groups of the respondents and preferred when there is no significant difference.

Accordingly, matching estimators were evaluated via matching the participant and non-participant households in common support region. Therefore, a matching estimator having balanced (insignificant mean differences in all explanatory variables) mean, bears a low pseudo $\mathrm{R}^{2}$ value and the one that results in large matched sample size is preferred.

3.5.2. Estimation of Treatment Effect

Choice of the matching algorithm was carried out from the nearest neighbor, caliper, and kernel methods. The choice of the estimator based on three criteria; namely, balancing test, Pseudo R-square and matched sample size. The matching estimator which balances more independent variables has low pseudo- $\mathrm{R}^{2}$ value and a result in large matched sample was chosen as being the best estimator of the data. Accordingly, kernel matching method with of (0.1) was found to be the best estimator of the data of consumption expenditure and asset building of urban agriculture practice.

Table 7: Average treatment effect on the treated

\begin{tabular}{lllllll}
\hline \multicolumn{2}{l}{ Variable sample } & Treated & Controls & Difference & S. E & T-stat \\
CEAE & Unmatched & 1504.85135 & 1111.31325 & 393.538098 & 45.3319816 & 8.68 \\
ATT & & 1515.52857 & 1083.10162 & 432.426948 & 54.9171077 & $7.87^{*}$ \\
ABC & Unmatched & 3.93243243 & 2.79518072 & 1.13725171 & 0.175224815 & 6.49 \\
ATT & & 3.94285714 & 2.8416805 & 1.10117664 & 0.211180233 & $5.21^{*}$ \\
\hline
\end{tabular}

Note: * indicate statistical significance at $10 \%$ respectively

Source: Own computation, 2019

As showed (Table 7), the Average Treatment effect on the Treated (ATT) was computed based on kernel $(0.1)$ matching method. Outcome variables are consumption expenditure per adult equivalent and asset building per capita which are measured in Ethiopia Birr and in unit respectively. The impact of urban agriculture on poverty reduction (by using household consumption expenditure) was based on a sample of matched treated and control groups, the estimated average treatment effect (ATT) significant effect on expenditure of participant households with significant $t$ - statistic (7.87) at 1 percent significance level $(\mathrm{p}<0.001)$. The average consumption expenditure of participant households in urban agriculture practice was higher by 432birr per adult equivalent in given monthly expenditure when compared with the average consumption expenditure of non-participant households, which was similar result with Belete(2015) finding that stated the urban agriculture yields both direct income through sales 
and indirect income through reduction of expenditures on food to participants.

The kernel (0.1) matching method result revealed that the durable asset building of the urban households who were the participant of urban agriculture practice was much greater with one unit per person than non-participants in given period. From the Table7, it is clear that the average treatment effect on the treated (ATT) of average consumption expenditure with t-value 7.87 and asset building with t-value 5.21, indicating the effective level of significance.

3.5.3 Sensitivity Test for Average Treatment Effect on the Treated

Sensitivity analysis is a strong identifying assumption and must be justified. According to Grilli \& Rampichini (2011), sensitivity analysis is the final diagnostic that must be performed to check the sensitivity of the estimated treatment effect to small changes in the specification of the propensity score. The results are insensitive to possible deviations emanating from the identified unconfoundedness assumption and therefore it holds shown to have a positive significant impact on consumption expenditure per adult equivalent and asset building per capita it should be promoted among urban households as a way of improving their livelihoods or reducing poverty (Annex- II).

\section{Conclusion and recommendation}

Urban agricultural practice had significantly positive impact on households' consumption and asset building. The sensitivity analysis also showed that the estimates are almost free from unobserved covariates. Furthermore, factors such as income from other sources, household size, access to extension services, access to water, access to improved inputs and access to credit were found to be important variables to determine urban households to participate.

Frequent and continuous training, technical advice and material support should be provided by the government to urban households to enhance the productivity and economic viability of urban agriculture. Government and NGOs could enhance the productivity of urban agriculture through creating awareness to urban households by providing appropriate improved farm inputs which are recommended fertilizer use, improved seeds, improved diseases and pesticides management practices that would help to address poverty. The agricultural research and extension activities need to consider improved agronomic practices along with urban agriculture in order to increase its production, and for the successful promotion, improvement and scaling up of good agronomic practices and extension should contact households individually as well as in group to be awarded in terms of urban agriculture is suitable to improve households' income and their asset building.

Water was found as one of important constraint that hinders urban households to not participate in urban agriculture practice in the study area. Hence, alternative water sources should be strengthened through digging wheel water and use low-cost water for urban agriculture production. Promoting use of credit and finance to urban households, the researcher recommends that the land use and administration of job process to formulate policy or strategy that tend to favor individual's land rights because this property rights structure is presumed to lead to more efficient forms of land use, as well as provide the property owners the ability to use the land as collateral for credit and they can be used the land as collateral for getting a loan. Therefore, findings of this study suggest that urban agriculture practice should be encouraged by Government and Non-government organizations through provision of credit, farm inputs, extension services and promotion of alternative water sources to increase its production there by reducing poverty among urban households so that it can be taken as an alternative poverty reduction policy strategy.

\section{References}

Arku et al. (2012). Africa quest for food security: what is the role of urban agriculture? Harare, Zimbabwe.The African Capacity Building Foundation.

Belete, B. (2015). Assessing the Contribution of Urban Agriculture to Urban Households:The Case of Boloso Bombe Town, Wolaita Zone, SNNPR, Ethiopia A Thesis Submitted to the School of Geography and Environmental Studies,School of Graduate Studies Haramaya University. unpublished.

Dereje. (2011). Contribution of Urban Agriculture for improving food security:The case of Bole Bulbula

Caliendo, M., \& Kopeinig, S. (2008). .some practical guidance for the implementation of propensity score matching. Journal of Economic Surveys, Vol. 22, No. 1, pp. 3172.

CSA. (2014). Central Statistical Agency of Ethiopia. Demographic and Health survey projected; Addis Ababa,Ethiopia.

Dehja, R. H., \& Wehba. (1999). Causal effects in non-experimental studies: Re-Evaluating the Evaluation of Training programs. Journal of the American statistical association, 94:448, 1053-1062.

Esubalewu, A. (2006). Determinants of Urban Poverty in DebreE Markos, Ethiopia.

G.Rezai, N.Shamsudin, Mohamed, Z., \& S.Juwaidah. (2014). Factor Influencing Public Participation in Urban Agriculture in Malaysia. International Journal of Social Science \& Human Behavior Study- IJSSHBS Volume 1, 55-58.

Gamhewage, P., Sivashankar, R. P., Mahaliyanaarachchi, A., Wijeratne, W., \& Hettiarachch, I. C. (2015). Women 
Participation in Urban Agriculture and its Influence on Family Economy - Sri Lankan.Vol. 10, No. 3,September. $192-206$.

Grilli, L., \& Rampichini, C. (2011). Propensity scores for the estimation of average treatment effects in observational studies.46P.

Guirkinger, C., \& Boucher, S. R. (2008). Credit constraints and productivity in Peruvian agriculture. Agricultural Economics, 39(3), 295-308.http://dx.doi.org/10.1111/j.1574-0862.2008.00 334.x.

Hossana Town Finance and Economic Development Office. (2014). Socio-economic profile of Hossana town, unpublished document. Hossana, Ethiopia. .

Jacobi, P., Amend, J., \& Kiango, S. (1999). Case Study about the Situation of Urban Agriculture in Dar es Salaam. Urban Vegetable Promotion Project, Dar es Salaam, Tanzania (unpublished).

Jongwe, A. (2013). Synergies between urban agriculture and urban household food security in Gweru City. Journal of Development and Agricultural Economics.Vol. 6(2), 59-66.

Onyango, C. L. (2011). Urban and Peri-Urban Agriculture as aPoverty Alleviation Strategy among Low Incomem Households:The Case of Orange Farm,South Johannesburg.

Pfeiffera, L., Feldmanb, L., \& Taylorc, J. (2009). Is off-farm income reforming the farm?Evidence from Mexico. Agricultural Economics 40, 125-138.

Rosembaum, P., \& Rubin, D. (1983). The central role of the propensity score in observational studies for causal effects. Biometrika, 70(1), 41-55.

Smith etal. (2001). Urban Agriculture:food, jobs, and sustainable cities. The United Nations Development Programme.

WFP. (2014). Ethiopia Comprehensive Food Security and Vulnerability Analysis (CFSVA).

Yamane, T. (1967). Statistics, An Introductory Analysis, 2nd Ed., New York: Harper and Row.

\section{Annex I}

- estat classification

Logistic model for ua

\begin{tabular}{c|cc|r}
\cline { 2 - 3 } Classified & D & True & Total \\
\hline+ & 59 & 23 & 82 \\
- & 24 & 70 & 94 \\
\hline Total & 83 & 93 & 176
\end{tabular}

Classified + if predicted $\operatorname{Pr}(\mathrm{D})>=.5$

True $D$ defined as ua $!=0$

\begin{tabular}{|c|c|c|}
\hline Sensitivity & $\operatorname{Pr}(+\mid D)$ & $71.08 \%$ \\
\hline Specificity & $\operatorname{Pr}(-\mid \sim D)$ & $75.27 \%$ \\
\hline Positive predictive value & $\operatorname{Pr}(\mathrm{D} \mid+)$ & $71.95 \%$ \\
\hline Negative predictive value & $\operatorname{Pr}(\sim D \mid-)$ & $74.47 \%$ \\
\hline False + rate for true $\sim D$ & $\operatorname{Pr}(+\mid \sim D)$ & $24.73 \%$ \\
\hline False - rate for true $D$ & $\operatorname{Pr}\left(\begin{array}{ll}-\mid & D\end{array}\right)$ & $28.92 \%$ \\
\hline False + rate for classified + & $\operatorname{Pr}(\sim D \mid+)$ & $28.05 \%$ \\
\hline False - rate for classified - & $\operatorname{Pr}(\mathrm{D} \mid-)$ & $25.53 \%$ \\
\hline Correctly classified & & $73.30 \%$ \\
\hline
\end{tabular}




\section{Annex-II}

Mantel-Haenszel (1959) bounds for variable ceae

$\begin{array}{rrrrr}\text { Gamma } & Q_{-} m h+ & Q_{-} m h- & p_{-} m h+ & p_{-} m h- \\ -1 & . & . & . & . \\ 1.05 & -.081139 & . & .532334 & . \\ 1.1 & -.081139 & -.081139 & .532334 & .532334 \\ 1.15 & . & -.081139 & . & .532334 \\ 1.2 & -.081139 & -.081139 & .532334 & .532334 \\ 1.25 & . & -.081139 & . & .532334 \\ 1.3 & . & -.081139 & . & .532334 \\ 1.35 & . & . & . & . \\ 1.4 & -.081139 & . & .532334 & . \\ 1.45 & -.081139 & -.081139 & .532334 & .532334 \\ 1.5 & . & -.081139 & . & .532334 \\ 1.55 & -.081139 & -.081139 & .532334 & .532334 \\ 1.6 & . & -.081139 & . & .532334 \\ 1.65 & -.081139 & -.081139 & .532334 & .532334 \\ 1.7 & -.081139 & -.081139 & .532334 & .532334 \\ 1.75 & -.081139 & -.081139 & .532334 & .532334 \\ 1.8 & -.081139 & .532334 & . \\ 1.85 & -.081139 & -.081139 & .532334 & .532334 \\ 1.9 & -.081139 & -.081139 & .532334 & .532334 \\ 1.95 & .532 & -.081139 & . & .532334 \\ 2 & -.081139 & -.081139 & .532334 & .532334\end{array}$

Gamma : odds of differential assignment due to unobserved factors Q mht : Mantel-Haenszel statistic (assumption: overestimation of treatment Q_mh- : Mantel-Haenszel statistic (assumption: underestimation of treatmer. p mht : significance level (assumption: overestimation of treatment effect p_mh- : significance level (assumption: underestimation of treatment effec 
. mhbounds abc, gamma $(1(0.05) 2)$

Mantel-Haenszel (1959) bounds for variable abc

$\begin{array}{rrrrr}\text { Gamma } & \text { l_mht } & \text { l_mh- }_{-} & p_{-} m h+ & p_{-} m h- \\ -1 & 1.0641 & 1.0641 & .143643 & .143643 \\ 1.05 & 1.10783 & 1.02703 & .133967 & .152202 \\ 1.1 & 1.14722 & .989343 & .125645 & .161248 \\ 1.15 & 1.18541 & .953804 & .117927 & .170091 \\ 1.2 & 1.2225 & .920198 & .11076 & .178735 \\ 1.25 & 1.25856 & .888336 & .104095 & .18718 \\ 1.3 & 1.29368 & .858057 & .097888 & .195431 \\ 1.35 & 1.32792 & .829217 & .092103 & .203491 \\ 1.4 & 1.36134 & .801693 & .086704 & .211365 \\ 1.45 & 1.39399 & .775374 & .081661 & .219059 \\ 1.5 & 1.42592 & .750165 & .076946 & .226578 \\ 1.55 & 1.45717 & .725978 & .072534 & .233926 \\ 1.6 & 1.48779 & .702737 & .068403 & .24111 \\ 1.65 & 1.51781 & .680373 & .064531 & .248134 \\ 1.7 & 1.54726 & .658824 & .060901 & .255004 \\ 1.75 & 1.57617 & .638034 & .057494 & .261726 \\ 1.8 & 1.60456 & .617954 & .054295 & .268303 \\ 1.85 & 1.63247 & .598536 & .05129 & .274741 \\ 1.9 & 1.65992 & .579741 & .048465 & .281045 \\ 1.95 & 1.68692 & .561528 & .045809 & .287219 \\ 2 & 1.71351 & .543865 & .04331 & .293267\end{array}$

Gamma : odds of differential assignment due to unobserved factors

l_mht : Mantel-Haenszel statistic (assumption: overestimation of treatment effect)

$\ell_{-}$mh- : Mantel-Haenszel statistic (assumption: underestimation of treatment effect)

p mht : significance level (assumption: overestimation of treatment effect)

$\mathrm{p}_{-}$mh- : significance level (assumption: underestimation of treatment effect) 